\title{
Abnormal xiphosurids in the Yale Peabody Museum Invertebrate Zoology collection
}

Russell D. C. Bicknell ${ }^{1, *}$ and Stephen Pates ${ }^{2,3}$

${ }^{1}$ Palaeoscience Research Centre, School of Environmental and Rural Science, University of New England, Armidale, New South Wales, 2351, Australia. rdcbicknell@gmail.com

${ }^{2}$ Department of Zoology, University of Oxford, Oxford, OX1 3PS, United Kingdom. stephen.pates@zoo.ox.ac.uk

${ }^{3}$ Institute of Earth Sciences, University of Lausanne, Lausanne, CH-1015, Switzerland.

* Corresponding author 


\section{ABSTRACT}

Xiphosurids are an archetypal group of chelicerates with extensive anatomical, physiological and palaeontological documentation. Despite this research, very little information is available concerning abnormal specimens of the group. Here we vastly increase the number of documented abnormal extant xiphosurids by identifying 17 specimens showing a range of abnormalities on the appendages, cephalothorax, thoracetron, and telson. These specimens include all extant species and the first documentation of abnormal Carcinoscorpius rotundicauda. We note that previous suggestions that the telson was the most commonly abnormal body part may reflect a speciesspecific bias and propose increased use of museum collections to understand these iconic organisms and their abnormalities.

KEYWORDS: abnormalities; Xiphosurida; Carcinoscorpius rotundicauda; Limulus polyphemus; Tachypleus gigas; Tachypleus tridentatus 


\section{Introduction}

True horseshoe crabs (order Xiphosurida within Chelicerata) have been, and continue to be, extensively studied arthropods due to their size and fossil record. The anatomical (e.g. Owen 1872; Lankester 1881; Shultz 2001; Bicknell et al. 2018a, c), biochemical (e.g. Kaplan et al. 1977), biomechanical (Bicknell et al. 2018b), ecological (e.g. Sokoloff 1978; Shuster 1982; Shuster and Sekiguchi 2009; Fairuz-Fozi et al. 2018), genetic (e.g. Sokoloff 1978; Obst et al. 2012) and palaeontological (e.g. Woodward 1879; Fisher 1984; Selden and Siveter 1987; Hauschke and Wilde 1991; Lamsdell 2013; 2016; Bicknell et al. 2018d) facets of horseshoe crabs have therefore been thoroughly documented. Recent research (Bicknell et al. 2018d) highlighted that extant and extinct horseshoe crab abnormalities are underexplored. Bicknell et al. (2018d) presented notes on all previous documented abnormal specimens (see van der Meer Mohr 1935; Shuster 1982; Jell 1989 for the majority of other abnormalities) and demonstrated abnormalities in both extant and extinct species. Here we further this work by reporting abnormalities on all extant xiphosurids species. Carcinoscorpius rotundicauda (Latreille, 1802) — the mangrove horseshoe crab sensu CartwrightTaylor et al. (2009), Limulus polyphemus (Linnaeus, 1758)— the Atlantic or American horseshoe crab, sensu Shuster et al. (2003), Tachypleus gigas (Müller, 1785)—the South Asian horseshoe crab, sensu Miyata et al. (1984), and Tachypleus tridentatus (Leach, 1819)—the Japanese horseshoe crab sensu Nakamura et al. (1976) — using specimens in the Yale Peabody Invertebrate Zoology collection. In doing so, we present new examples of abnormalities (including an apparently rare abnormal appendage) and the first documented examples of abnormalities in C. rotundicauda.

\section{Abnormalities: causes and forms}

Following Owen (1985) and Bicknell et al. (2018d), the term abnormality describes a misshapen or missing exoskeletal section, or an additional and unusual growth. Although original cause may be unknown, three major abnormality-inducing pathways have been suggested: injuries, teratologies, and pathologies (Bicknell et al. 2018d modified the definitions in Owen 1985—originally applied to trilobites—to xiphosurid abnormalities). 
Injuries: result of mechanical damage induced by predators, or self-inflicted accidentally during moulting, mating, or burrowing. Generally 'V', 'W', 'U', or ' $L$ ' shaped embayments or indents in the xiphosuran exoskeleton. Scar formation (cicatrisation) occurs at injury site, with partial regeneration of injured areas during subsequent moulting events. Injuries can impact one side of the exoskeleton (unilateral) or both sides thereof (bilateral).

Teratologies: developmental and genetic aberrations. Can result in the additional, abnormal or failed growth of spines and body parts (e.g. segments, spines).

Pathologies: atrophied tissue caused by disease, or abnormal growth of exoskeleton around a parasitic intrusion. 


\section{Methods}

This approach develops on Jell (1989) and Bicknell et al. (2018d) who reported abnormal specimens from museum collections. All dry and wet xiphosurid specimens from the Yale Peabody Museum Invertebrate Zoology (YPM IZ) collection were reviewed for abnormalities (n=127). Abnormal specimens were photographed with a Canon D60 under LED lighting in the Yale Peabody Museum Division of Invertebrate Paleontology. Wet specimens were removed from alcohol and imaged. Images were stacked using Helicon Focus 6 (Helicon Soft Limited) stacking software. Injured trilobite specimens with recovering thoracic spines from the South Australia Museum (SAM), Adelaide and Museo de Ciencias Naturales de la Universidad de Zaragoza (MPZ), Spain. 


\section{Results}

Carcinoscorpius rotundicauda

A total of 14 Carcinoscorpius rotundicauda specimens were reviewed and four adult specimens with abnormalities to the cephalothorax, thoracetron, and telson were documented. YMP IZ 103383 shows a bilaterally expressed cephalothoracic abnormality with 'W'-shaped indentations on both genal spines (Fig. 1A, C, D). YPM IZ 55595 has a symmetrical ' $U$ '-shaped indentation on the posterior right thoracetron (Fig. 1B, E). The right thoracetron side has five moveable spine notches, one fewer than the left side. YPM IZ 103384 displays an asymmetric ' $U$ '-shaped indentation on the anterior right thoracetron and one fewer movable spines on the right side (four) than the left (five) (Fig. 2A, B). YPM IZ 55594 has a kink within the last fifth of the telson (Fig. 2C, D).

\section{Limulus polyphemus}

A total of 88 Limulus polyphemus specimens were reviewed. YMP IZ 103398, a juvenile specimen, was the only abnormal wet specimen and has a stunted, left-curved telson (Fig. 3D, E). YMP IZ 30231 has an injured thoracetron and telson (Fig. 3A-C). The thoracetron has a 'W'-shaped indentation in the middle-left side, and lacks a moveable spine, and the associated spine notch (Fig. 3A, C). The telson has a slight kink in the last third of the tail-spine (Fig. 3A, B). YPM IZ 55601, the largest L. polyphemus specimen in the YPM IZ collection (ca. $52 \mathrm{~cm}$ long), has a kink in the first third of the telson (Fig. 4A, B) and movable spines on the right posterior thoracetron that are a third the size of spines on the left side (Fig. 4A, D). YPM IZ 55579 is the only specimen documented here with an appendage abnormality: a shortened apotele on the right pushing leg (cephalothoracic appendage VII) (Fig. 4 C, E).

\section{Tachypleus gigas}

A total of 17 Tachypleus gigas specimens were reviewed. Six abnormal, adult $T$. gigas specimens were documented, five with cephalothoracic abnormalities, and one with a thoracetronic abnormality. This species had the most diverse range of shapes of abnormalities in the collection. YPM IZ 103380 displays an abnormal left cephalothoracic genal spine with a 'W'-shaped injury 
comparable to the embayment in a Carcinoscorpius rotundicauda specimen (Fig 1A, C, D) and a small, oval shaped indentation (Fig. 5A, D). YPM IZ 55599 shows a rounded genal spine with a protrusion developing dorsally from the rounded edge (Fig. 5B, F). YPM IZ 103366 has an 'O'shaped impression on the left anterior cephalothorax that deformed the surrounding exoskeleton (Fig. 5C, E). YPM IZ 10336 displays two injuries to the right cephalothorax (Fig. 6A, D, E). The cephalothoracic boarder has a small ' $U$ '-shaped embayment on the right anterior section (Fig. 6A, D) and the posterior right genal spine has two terminal points (Fig. 6A, E). YPM IZ 103382 possesses a large ' $U$ '-shaped indentation on the centre left cephalothorax (Fig. 6B, F). This indentation is coupled with an ovate hole located dorsally above from the indentation. The hole has evidence of recovery. The only $T$. gigas specimen with a thoracetronic abnormality was a female specimen, YPM IZ 103377 (Fig. 6C, G). This specimen has five moveable spine notches on the right side, as opposed to six, and two moveable spines developed in the fourth notch (Fig. 6G).

\section{Tachypleus tridentatus}

A total of 8 Tachypleus tridentatus specimens were reviewed, and three abnormal T. tridentatus specimens (two adults, one juvenile) were documented. These displayed cephalothoracic, thoracetronic, and telson abnormalities. A large adult female specimen, YPM IZ 55581, has a bilateral thoracetronic abnormality (Fig. 7A-C). The left thoracetron has a posterior movable spine removed and another stunted moveable spine (Fig. 7B). The right thoracetron has two stunted anterior moveable spines, the most anterior of which is fused to the thoracetron (Fig. 7C). The other adult specimen, YPM IZ 2430, shows a 'U'-shaped indentation in the left anterior cephalothoracic margin (Fig. 7D, E). The juvenile specimen, YPM IZ 103381, has a left-curved telson (Fig. 7F, G). 


\section{Discussion}

Injury is the most common cause of abnormality observed here. The ' $W$ ' and ' $U$ ' shaped embayments and indents to cephalothoraces and thoracetrons are diagnostic of mechanical damage. Only one specimen (YPM IZ 103382) shows evidence of scarring and recovery, with all other injuries having therefore likely undergone some level of regeneration and therefore multiple moulting events. The ' $U$ ' shape of some injuries could indicate either an injury from tearing softer exoskeleton after a moutling event and/or an injury that has undergone substaintail recovery. Unequal numbers of movable spines on thoracetron sides and missing spine notches are also evidence of injuries (YMP IZ 30231, YPM IZ 55595, and YPM IZ 103384; Figs. 1B, E, 2A, B, 3A, C). Examples of stunted, absent, or otherwise abnormal spines may reflect a teratological cause. The exception to this is YPM IZ 103377 (Fig. 6C, G) where two spines have developed in one thoracetronic spine notch. This abnormality likely resulted from a previously injured notch. This is similar to the development of two spines from an injured single thoracic section is seen in Cambrian trilobites (Fig. 8) (Pates et al. 2017). One case, the 'O'-shaped impression in the left anterior cephalothorax of YPM IZ 103366, could be a pathology associated with a parasite. Shuster (1982), Botton and Loveland (1989) and Bicknell et al. (2018d) all observed that telson abnormalities were the most frequently documented horseshoe crab abnormalities. The Limulus polyphemus specimens documented here did have more telson abnormalities than other types; however, the three other horseshoe crab species display more cephalothoracic and thoracetronic abnormalities (Table 1). In Tachypleus gigas abnormalities are incurred most often on the cephalothorax, whereas in Carcinoscorpius rotundicauda and T. tridentatus they are found on all sections of the exoskeleton in similar proportions. Patterns of abnormalities in extant horseshoe crabs may therefore be species specific and could potentially relate to the environmental conditions inhabited by the taxa or predatory groups targeting the different species. As the small sample size presented herein cannot offer conclusive statistical support, a larger quantitative study of bulk 
samples considering large populations of all four species is needed to confirm or reject this hypothesis.

Bursey (1977) and Clare et al. (1990) represent the few attempts at intentionally damaging Limulus polyphemus specimens to explore how the injuries recovered at a cellular level. However, no attempts have been made to replicate naturally occurring abnormalities in laboratory. An extension of Clare et al. (1990) could be to inflict injuries to specimens raised and housed in lab to document how the individuals recovered at the macro-scale in subsequent moulting events. This experiment would allow researchers to determine how horseshoe crab exoskeletons recover from potentially traumatic damage and to suggest the extent of recovery (if any) for naturally produced abnormalities. Furthermore, data on injury recovery across multiple moulting events will aid palaeontologists interested in understanding how extinct limulids and trilobites recovered from injuries (sensu Pates et al. 2017, fig. 10).

Amazing “discoveries [are] made in museum draws” (Gould 1989:80) as is exemplified by the research within the Smithsonian that sparked the Burgess Shale revolution and restudy of the Cambrian Explosion. Here, we have conducted similar research, an approach that has two important uses. (1) Museum collections often go un-considered for decades; however, they are often easily accessible, rich, and provide diverse records of extant and extinct organisms. (2) These collections aid in the conservation of endangered species. Today, through harvesting for biomedical research and food (Botton 2001; Hsieh and Chen 2009; John et al. 2011; Nelson et al. 2015; Kwan et al. 2016; Fairuz-Fozi et al. 2018) horseshoe crabs are becoming a threatened group, despite having survived four mass-extinctions since their origination early in the Phanerozoic (Størmer 1952; 1955; Selden and Siveter 1987; Rudkin and Young 2009; Van Roy et al. 2010). Museum collections that have been amassed over decades therefore represent one of the best potential avenues for understanding these still enigmatic organisms and allow them to recover to stable population levels. 


\section{Conclusion}

Our study of extant xiphosurids with abnormalities reports 17 new examples of abnormal specimens and the first examples of abnormal Carcinoscorpius rotundicauda. The majority of documented abnormalities are considered injuries. Our data suggest that abnormality patterns may be species specific and potentially reflect environmental or predatory influences. We note that museum collections, such as the YPM IZ, are ideal for further documenting interesting features on these iconic species. 
Acknowledgements: This research was supported by funding from an Australian Postgraduate Award (to R.D.C.B.), a Charles Schuchert and Carl O. Dunbar Grants-in-Aid award (to R.D.C.B.), and an Oxford-St Catherine's Brade-Natural Motion Scholarship (to S.P). We thank Susan Butts and Jessica Utrup for use of the Yale Peabody Museum Division of Invertebrate Paleontology camera. We thank Lourdes Rojas for help with YMP IZ specimens. Finally, we thank the editor Patrick Sweeney, and the two reviewers Olda Fatka and Daniel Drew for their useful and supportive comments. 


\section{Literature Cited}

Bicknell, R.D.C., A.J. Klinkhamer, R.J. Flavel, S. R. J., Wroe AND J.R. PATERSON. 2018a. A 3D anatomical atlas of appendage musculature in the chelicerate arthropod Limulus polyphemus. PLoS ONE 13(2):e0191400. 10.1371/journal.pone.0191400

—, J.A. Ledogar, S. Wroe, B.C. GutZler, W.H. WATSON III AND J.R. PATERSON 2018b.

Computational biomechanical analyses demonstrate similar shell-crushing abilities in modern and ancient arthropods. Proceedings of the Royal Society B: Biological Sciences: in press.

10.1098/rspb.2018.1935

—, J.R. Paterson, J.-B. CARon J. -B. And C.B. Skovsted C. B. 2018c. The gnathobasic spine microstructure of Recent and Silurian chelicerates and the Cambrian artiopodan Sidneyia: Functional and evolutionary implications. Arthropod Structure \& Development 47(1):12-24. 10.1016/j.asd.2017.12.001

—., S. PATES. AND M.L BotTON 2018d. Abnormal xiphosurids, with possible application to Cambrian trilobites. Palaeontologia Electronica 20(2):1-17. 10.26879/866

BotTON, M.L. 2001. The conservation of horseshoe crabs: What can we learn from the Japanese experience? In: Tanacredi J. T., editor. Limulus in the Limelight. New York: Springer. pp. $41-51$.

— AND R.E LOVELAND 1989. Reproductive risk: high mortality associated with spawning by horseshoe crabs (Limulus polyphemus) in Delaware Bay, USA. Marine Biology 101(2):143151. $10.1007 / \mathrm{BF} 00391453$

BURSEY, C. R. 1977. Histological response to injury in the horseshoe crab, Limulus polyphemus. Canadian Journal of Zoology 55(7):1158-1165

CARTWRight-TAYlor, L., J. LeE AND C.C. Hsu. 2009. Population structure and breeding pattern of the mangrove horseshoe crab Carcinoscorpius rotundicauda in Singapore. Aquatic Biology 8(1):61-69. 10.3354/ab00206 
Clare, A.S., G. Lumb, P.A Clare AND J.D. Costlow JR. 1990. A morphological study of wound response and telson regeneration in postlarval Limulus polyphemus (L.). Invertebrate Reproduction \& Development 17(1):77-87. 10.1080/07924259.1990.9672091

FairuZ-Fozi, N., B. Satyanarayana, N.A.M. Zauki, N. A. M.A.M. Muslim, M.-L. Husain, S. IBRAHIM AND B.R. NELSON . 2018. Carcinoscorpius rotundicauda (Latreille, 1802) population status and spawning behaviour at Pendas coast, Peninsular Malaysia. Global Ecology and Conservation: in press. 0.1016/j.gecco.2018.e00422

FISHER, D.C. 1984. The Xiphosurida: archetypes of bradytely? In: N. Eldredge and S.M. Stanley, eds. Living fossils. New York: Springer. pp. 196-213.

GouLD, S.J. 1989. Wonderful Life: The Burgess Shale and the nature of history. New York: W. W. Norton \& Company. pp. 347.

HAUSCHKE, N. AND V. WILDE. 1991. Zur Verbreitung und Ökologie mesozoischer Limuliden. Neues Jahrbuch für Geologie und Paläontologie, Abhandlungen 183(1-3):391-411.

HSIEH, H.-L. AND C.-P. CHEN. 2009. Conservation program for the Asian horseshoe crab Tachypleus tridentatus in Taiwan: characterizing the microhabitat of nursery grounds and restoring spawning grounds. In: In: J.T. Tanacredi, M.L. Botton and D.R. Smith, eds. Biology and conservation of horseshoe crabs. Springer. pp. 417-438.

JELL, P.A. 1989. Some aberrant exoskeletons from fossil and living arthropods. Memoirs of the Queensland Museum 27(2):491-498.

John, B.A., K.C.A. JaLAL, K. ZALEHA, P. ARMStrong And B.Y. KMARUZZAMAn. 2011. Effects of blood extraction on the mortality of Malaysian horseshoe crabs (Tachypleus gigas). Marine and Freshwater Behaviour and Physiology 44(5):321-327. 10.1080/10236244.2011.642505

KAPLAN, R., S.S.L. Li AND J.M. KeHOE 1977. Molecular characterization of limulin, a sialic acid binding lectin from the hemolymph of the horseshoe crab, Limulus polyphemus. Biochemistry 16(19):4297-4303. 
KwAn, B.K.Y., H.-L. HsIEH, S.G. Cheung AND P.K.S. ShIn 2016. Present population and habitat status of potentially threatened Asian horseshoe crabs Tachypleus tridentatus and Carcinoscorpius rotundicauda in Hong Kong: a proposal for marine protected areas. Biodiversity and Conservation 25(4):673-692. 10.1007/s10531-016-1084-z

LAMSDELL, J.C. 2013. Revised systematics of Palaeozoic 'horseshoe crabs' and the myth of monophyletic Xiphosura. Zoological Journal of the Linnean Society 167(1):1-27. 10.1111/j.1096-3642.2012.00874.x

—2016. Horseshoe crab phylogeny and independent colonizations of fresh water: ecological invasion as a driver for morphological innovation. Palaeontology 59(2):181-194. 10.1111/pala.12220

LANKESTER, E.R. 1881. Limulus an Arachnid. Quarterly Journal of Microscopical Science 23:504649.

LATREILLE, P.A. 1802. Histoire naturelle, générale et particulière, des crustacés et des insectes. pp. 467.

LEACH, W.E. 1819. Entomostraca. Dictionaire des Science Naturelles. Paris: Levrault and Schoell. pp. 537.

LINNAEUS, C. 1758. Systema naturce per regna tria naturce, secundum classes, ordines, genera, species, cum characteribus, differentiis, synonymis, locis. Laurentius Salvius, Holmia.

LU, Y. 1950. On the genus Redlichia with description of its new species. Geological Review 15:157-170. (In Chinese)

MiYATA, T., K. UsUI AND S. IWANAGA 1984. The amino acid sequence of coagulogen isolated from southeast Asian horseshoe crab, Tachypleus gigas. The Journal of Biochemistry 95(6):17931801.

MülLER, O.F. 1785. Entomostraca seu Insecta Testacea, quae in aquis Daniae et Norvegiae reperit, descripsit et iconibus illustravit. Leipzig and Copenhagen: Symtibus Bibliopolii J.G. Mülleriani, Müller, O. F. Lipsiae et Havniae. 
NAKAmura, S., S. IWANAGA, T. HARADA AND M. NiwA 1976. A clottable protein (coagulogen) from amoebocyte lysate of Japanese horseshoe crab (Tachypleus tridentatus). Its isolation and biochemical properties. The Journal of Biochemistry 80(5):1011-1021.

Nelson, B.R., B. Satyanarayana, J.M.H. Zhong, F. Shaharom, M. Sukumaran ANd A. CHATTERJI. 2015. Episodic human activities and seasonal impacts on the Tachypleus gigas (Müller, 1785) population at Tanjung Selangor in Peninsular Malaysia. Estuarine, Coastal and Shelf Science 164:313-323. 10.1016/j.ecss.2015.08.003

Obst, M., S. FAurby, S. Bussarawit AND P. FunCH. 2012. Molecular phylogeny of extant horseshoe crabs (Xiphosura, Limulidae) indicates Paleogene diversification of Asian species. Molecular Phylogenetics and Evolution 62(1):21-26. 10.1016/j.ympev.2011.08.025

OWEN, R. 1872. On the anatomy of the American King-crab (Limulus polyphemus, Latr.). Transactions of the Linnean Society of London 28(3):459-506.

OwEN, A. W. 1985. Trilobite abnormalities. Transactions of the Royal Society of Edinburgh: Earth Sciences 76(2-3): 255-272.

PATES, S., R.D.C. BiCKNell, A.C. DALEy And S. ZAmORA. 2017. Quantitative analysis of repaired and unrepaired damage to trilobites from the Cambrian (Stage 4, Drumian) Iberian Chains, NE Spain. Palaios 32(12): 750-761.

PRADO, M.C., E. VerneuIL AND J. BARRANDE. 1860. Sur l'existence de la faune primordialcdans la Châıne Cantabrique: Bulletin de la Société Géologique de France, 2(17): pp.516-542.

RuDKIN, D.M. AND G.A YounG. 2009. Horseshoe crabs-an ancient ancestry revealed. In: J.T. Tanacredi, M.L. Botton and D.R. Smith, eds. Biology and conservation of horseshoe crabs. Boston: Springer. pp. 25-44.

SELDEN, P.A. AND D.J SIVETER. 1987. The origin of the limuloids. Lethaia 20(4):383-392. 10.1111/j.1502-3931.1987.tb02060.x 
SHULTZ, J.W. 2001. Gross muscular anatomy of Limulus polyphemus (Xiphosura, Chelicerata) and its bearing on evolution in the Arachnida. Journal of Arachnology 29(3):283-303. 10.1636/0161-8202(2001)029[0283:gmaolp]2.0.co;2

SHUSTER, C.N. 1982. A pictorial review of the natural history and ecology of the horseshoe crab Limulus polyphemus, with reference to other Limulidae. Progress in Clinical and Biological Research 81:1-52.

—, R.B. BARLOW AND H.J. BROCKMANN. 2003. The American horseshoe crab. USA: Harvard University Press.

— AND SEKIGUCHI, K. 2009. Basic habitat requirements of the extant species of horseshoe crabs (Limulacea). In: J.T. Tanacredi, M.L. Botton and D.R. Smith, eds. Biology and conservation of horseshoe crabs. Springer. pp. 115-129.

SOKOLOFF, A. 1978. Observations on populations of the horseshoe crab Limulus (= Xiphosura) polyphemus. Researches on Population Ecology 19(2):222-236. 10.1007/BF02518829

STØRMER, L. 1952. Phylogeny and taxonomy of fossil horseshoe crabs. Journal of Paleontology 26(4):630-640.

— 1955. Merostomata. In: Moore R.C., editor. Treatise on Invertebrate Paleontology, Part P, Arthropoda 2. University of Kansas, Lawrence, Kansas: Geological Society of America. pp. $4-41$.

VAN DER MEER MoHR, J.C. 1935. Sur quelques malformations chez la limule, Tachypleus gigas. Miscellanea Zoologica Sumatrana 87:1-3.

VAn Roy P., P.J. ORR, J.P. BotTing, L.A. Muir, J. Vinther, B. LefEBVRE, K. EL HARIRI AND D.E.G. BRIGGs 2010. Ordovician faunas of Burgess Shale type. Nature 465(7295):215-218. WoODWARD, H. 1879. Contributions to the knowledge of fossil Crustacea. Quarterly Journal of the Geological Society 35(1):549-556. 


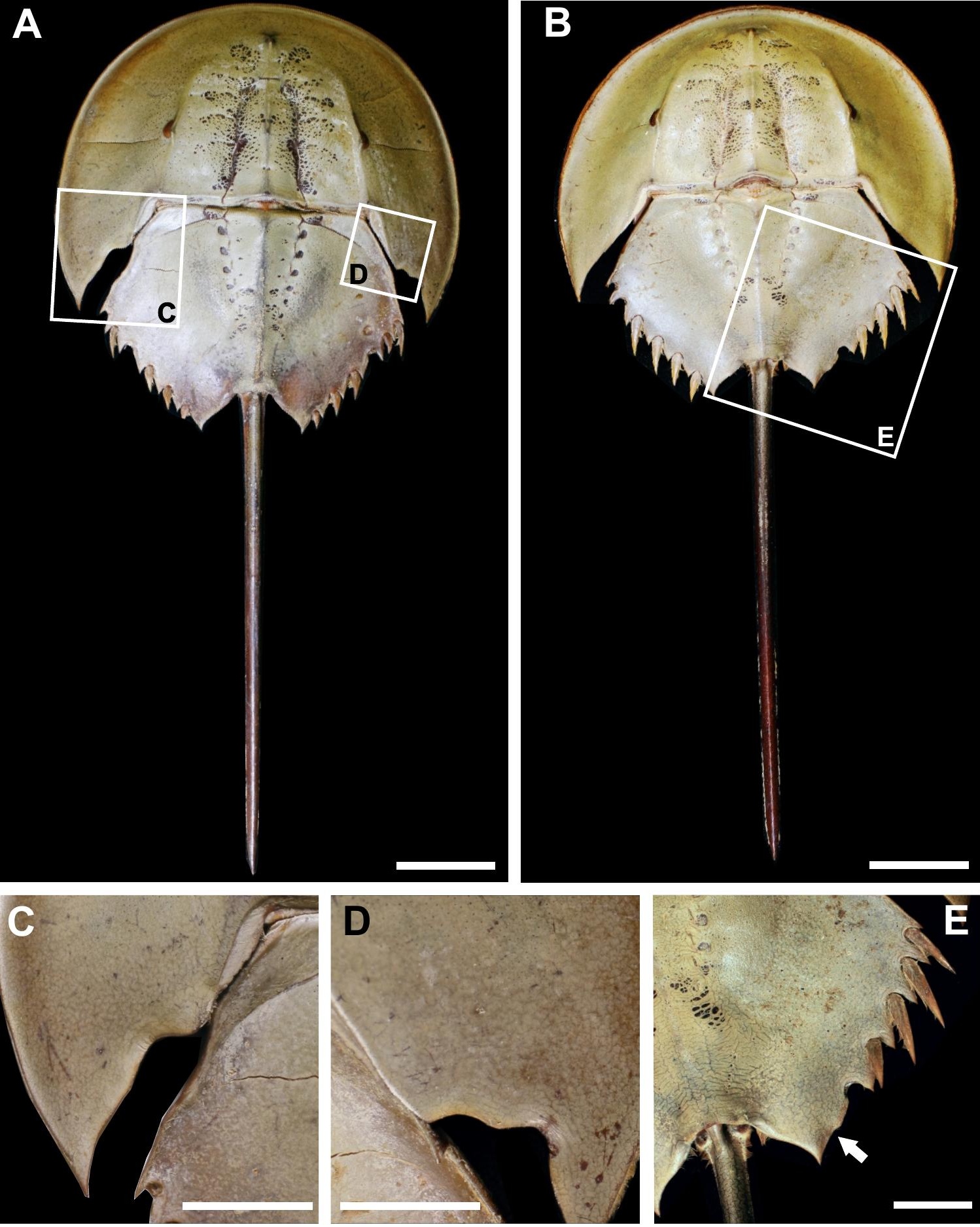


FIGURE 1. Carcinoscorpius rotundicauda specimens with cephalothoracic and thoracetronic abnormalities. (A, C, D) 'W'-shaped indentation to the genal spines (YMP IZ 103383). (C) Close up of left indentation. (D) Close up of right indentation. (B, E) 'U'-shaped indentation in thoracetron (YPM IZ 55595). (E) Close up of indentation (white arrow). All images in dorsal view. Scale bars: (A, D) $3 \mathrm{~cm}$; (B, C, E) $1.5 \mathrm{~cm}$. 


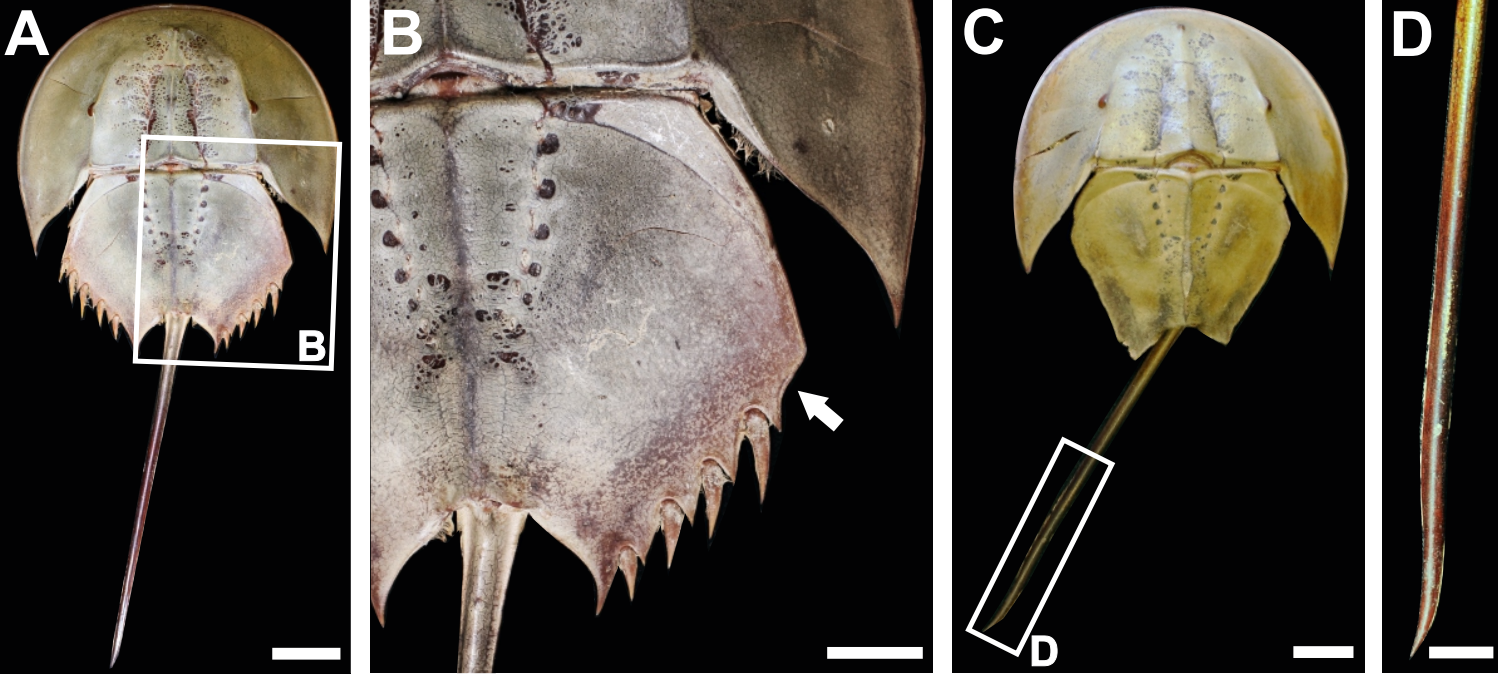




\section{FIGURE 2. Carcinoscorpius rotundicauda specimens with thoracetronic and telson}

abnormalities. (A, B) Carcinoscorpius rotundicauda with 'U'-shaped indentation on thoracetron (YMP IZ 103384) (B) Close up of indentation, white arrow. (C, D) Carcinoscorpius rotundicauda with kinked telson (YMP IZ 55594). (D) Close up of telson. All images in dorsal view. Scale bars: (A) $3 \mathrm{~cm}$; (B) $1.5 \mathrm{~cm}$; (C) $2 \mathrm{~cm}$; (D) $0.5 \mathrm{~cm}$. 

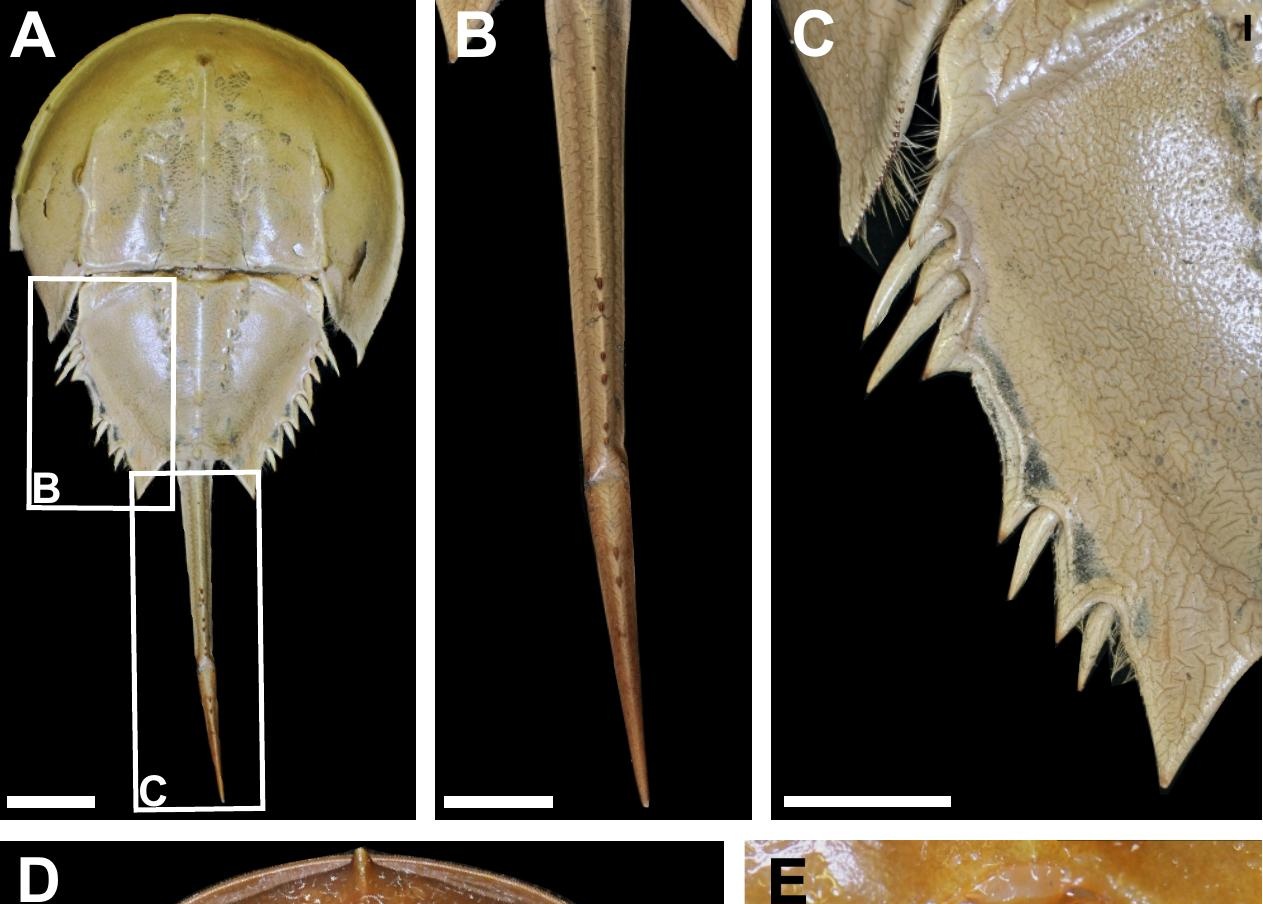

D
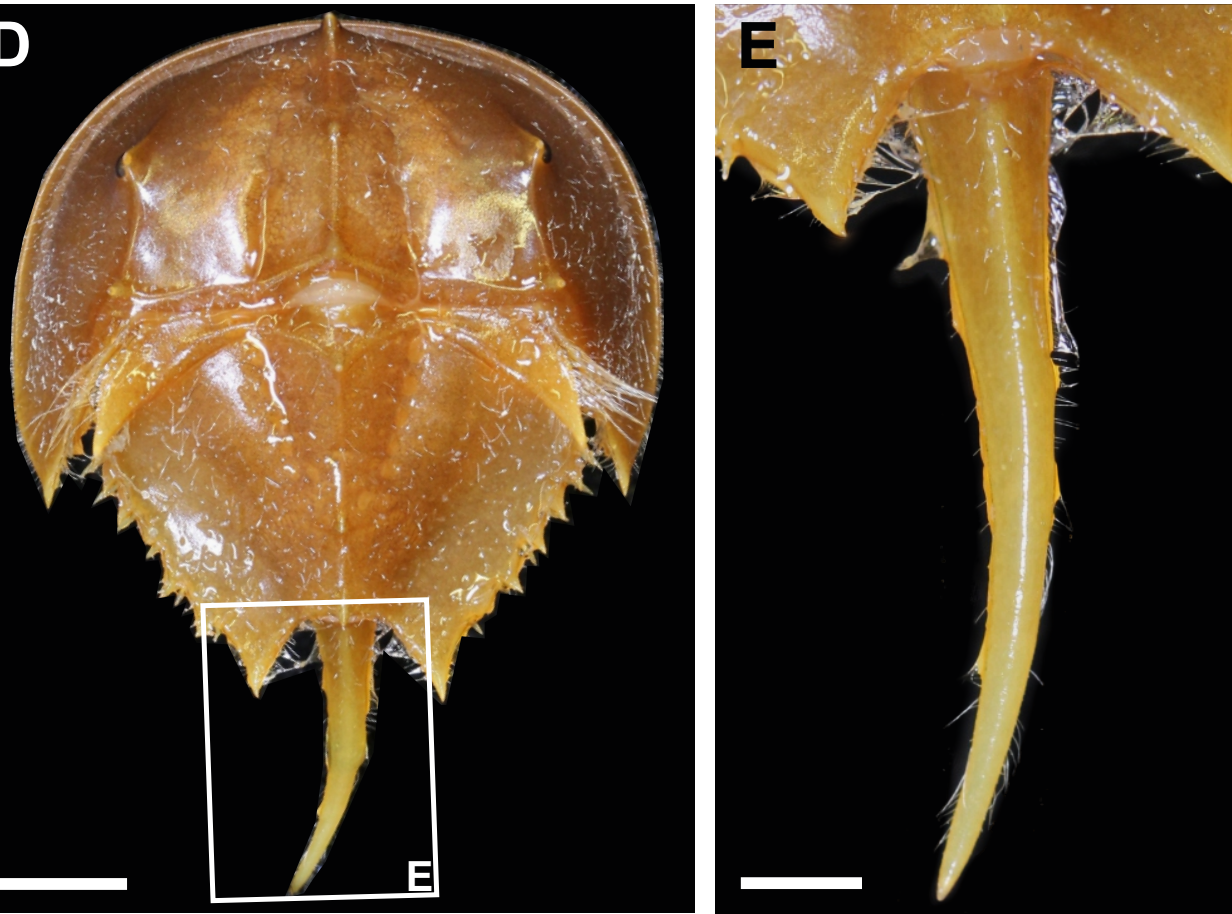
FIGURE 3: Limulus polyphemus specimens with thoracetronic and telson abnormalities (A-C) Limulus polyphemus with kinked telson and abnormal thoracetron (YPM IZ 30231). (B) Close up of kinked telson. (C) Close up of 'W'-shaped indentation. (D, E) Juvenile Limulus polyphemus (wet specimen) with left-curved telson (YPM IZ 103398). (E) Close up of telson. All images in dorsal. Scale bars: (A) $3 \mathrm{~cm}$; (B, C) $1.5 \mathrm{~cm}$; (D) $1 \mathrm{~cm}$; (E) $0.25 \mathrm{~cm}$. 
FIGURE 4. Limulus polyphemus specimens with abnormal moveable spines, appendages and telson. (A, B, D) Shortened moveable spines and kinked telson (YPM IZ 55601) (B) Close up of kinked telson. (D) Close up of shortened moveable spines (white arrows). (C, E) Abnormal pushing leg (YPM IZ 55579). (E) Close up damaged appendage (white arrow). (A, B, D) in dorsal view. (C, E) in ventral view. Scale bars: (A, C) $3 \mathrm{~cm}$; (B) $0.75 \mathrm{~cm}$; (D, E) $1.5 \mathrm{~cm}$. 
$\mathbf{A}$

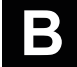

D

F E

8)

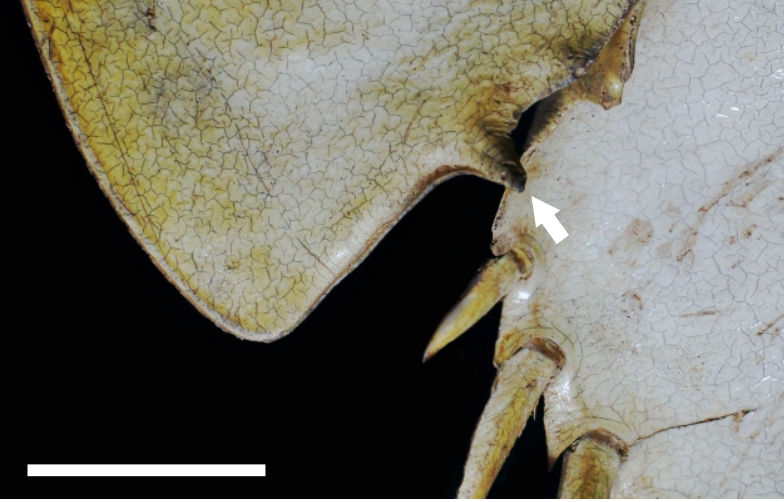


FIGURE 5. Tachypleus gigas specimens with abnormal cephalothoraxes. (A, D) 'W'-shaped indentation and oval-shaped indentation on left genal spine (YPM IZ 103380). (A) White arrow indicates abnormality. (D) Close up of abnormalities. White arrow: 'W'-shaped indentation, grey arrow: oval-shaped indentation (B, F) Rounded genal spine with protrusion (white arrow) (YPM IZ 55599). (F) Close up of protrusion (white arrow). (C, E) ‘O’-shaped impression in the left anterior cephalothorax (white arrow) (YPM IZ 103366). (E) Close up of impression. (A-C, F) in dorsal view. (D-F) in lateral view. Scale bars: (A-C) 3 cm; (D, F, G) 1.5 cm; (E) 2 cm. 
$\mathbf{A}$
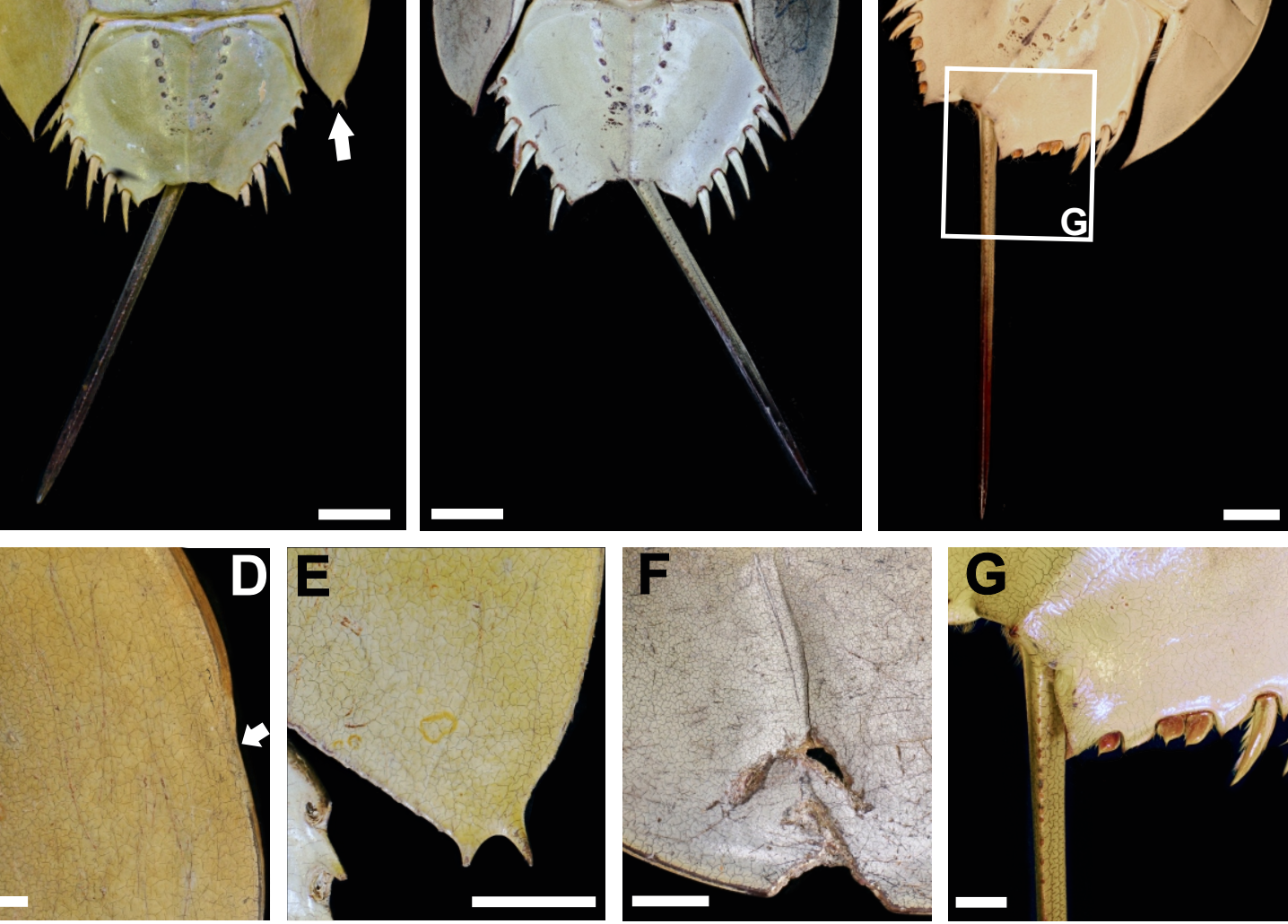
FIGURE 6. Tachypleus gigas specimens with abnormal cephalothoraxes and thoracetrons. (A, D, E) 'U'-shaped embayment on right anterior cephalothorax and abnormal right genal spine (white arrows) (YPM IZ 10336). (D) Close up of 'U'-shaped embayment (white arrow). (E) Close up of two genal spine points. (B, F) 'U'-shaped indentation in centre left cephalothorax (YPM IZ 103382). (F) Close up of indentation and ovate hole. Hole is scarred. (C, G) Female specimen with abnormal right thoracetron (YPM IZ 103377). (G) Close up of thoracetron with two moveable spines in the same notch. (A-C, G) in dorsal view. (E) in lateral view. Scale bars: (A, B) $3 \mathrm{~cm}$; (C, F) $2 \mathrm{~cm}$; (D, E) $1 \mathrm{~cm}$. 
$\mathbf{A}$

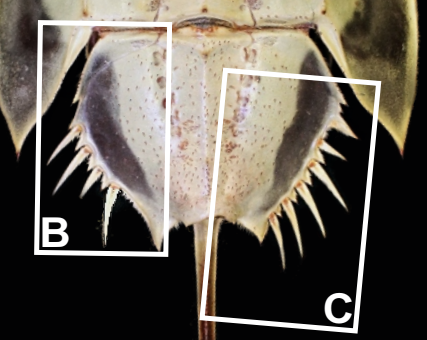

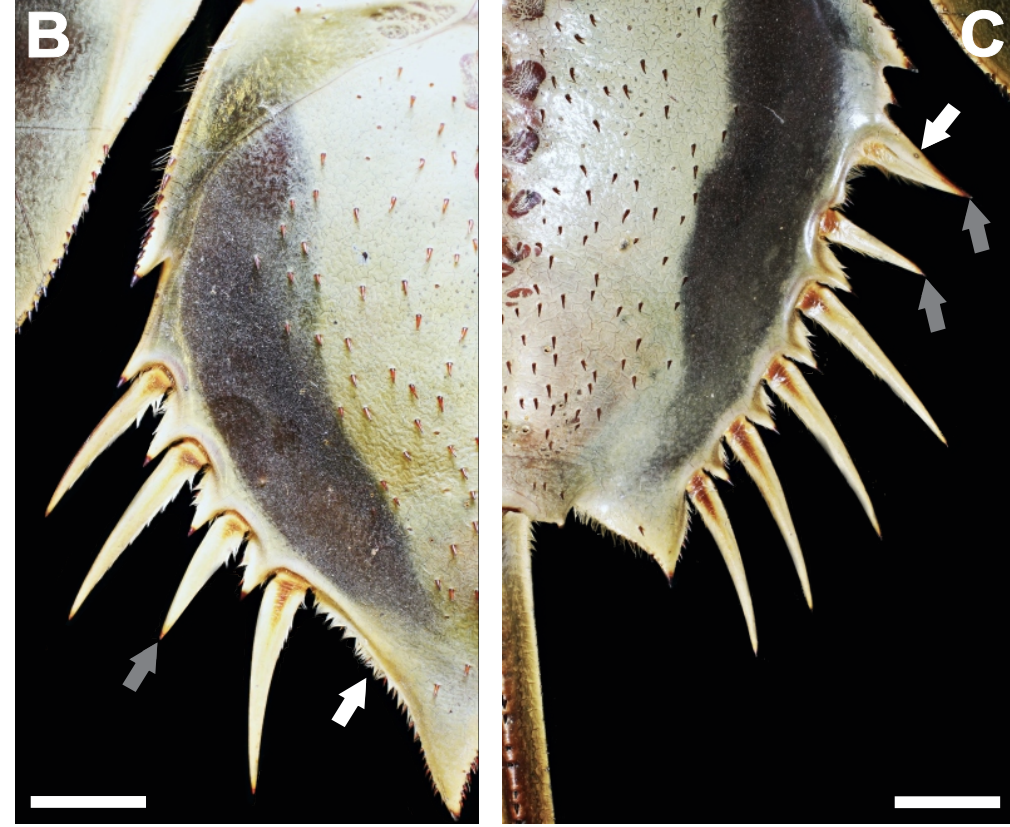
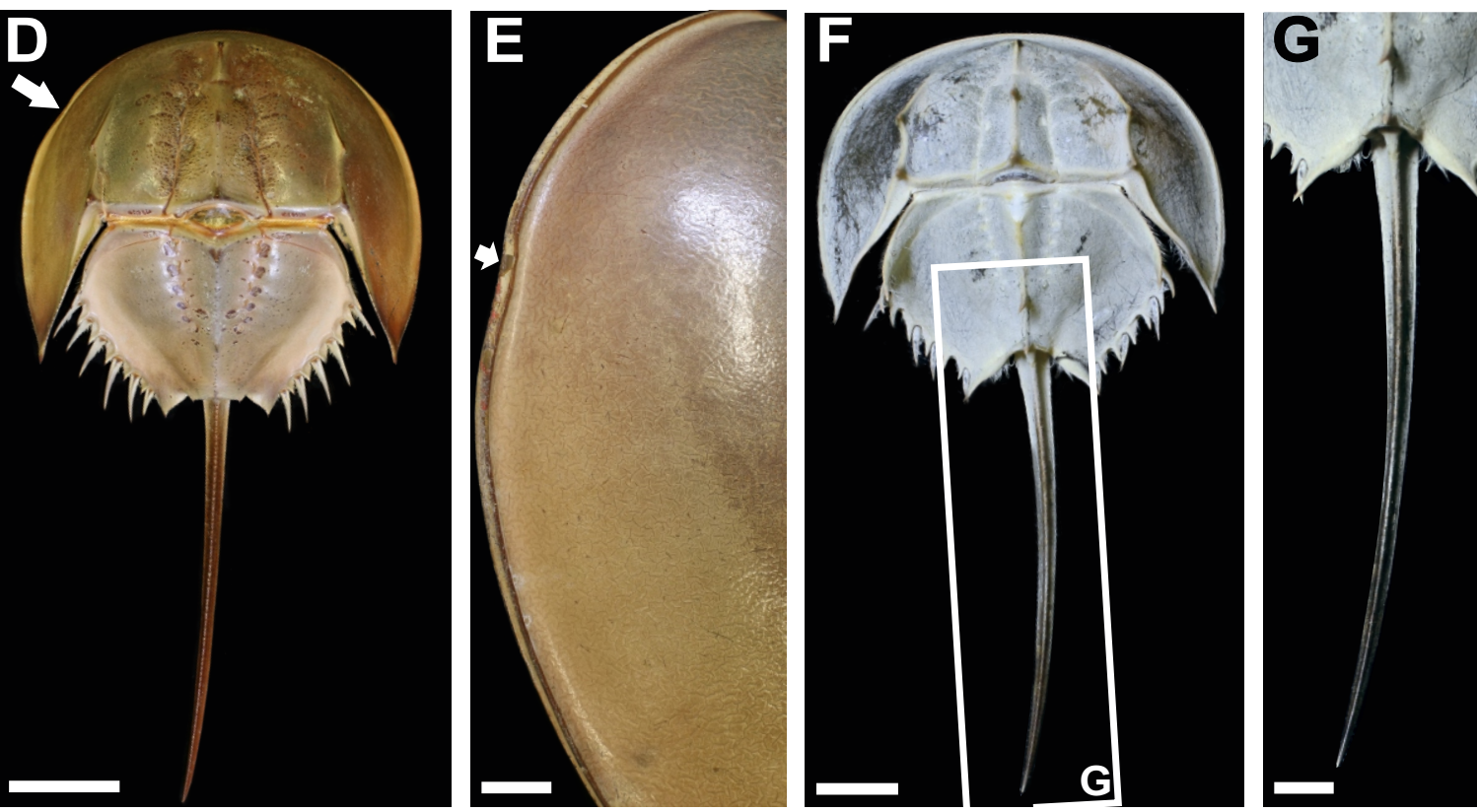
FIGURE 7. Tachypleus tridentatus specimen with abnormalities. (A-C) Female specimen with bilateral, thoracetronic abnormalities (YPM IZ 55581). (B) Left thoracetron with movable spine removed (white arrow) and stunted spine (grey arrow). (C) Right thoracetron with two stunted moveable spines (grey arrows) and a spine fused to thoracetron (white arrow). (D, E) 'U'-shaped indentation in the left anterior cephalothorax (white arrow) (YPM IZ 2430) (E) Close up of indentation (white arrow). (F, G) Juvenile with left-curved telson (YPM IZ 103381). (G) Close up of telson. (A-D, F, G) in dorsal view. (E) in lateral view. Scale bars: (A, D) 6 cm; (B, C) 1.5 cm; (E, F) $1 \mathrm{~cm}$; (G) $0.5 \mathrm{~cm}$. 


\section{FIGURE 8. Cambrian trilobites with multiple thoracic spines recovering in same thoracic}

segment. (A, B) Redlichia takooensis Lu, 1950 from lower Cambrian (Series 2, Stage 4) Emu Bay Shale, Kangaroo Island, South Australia (SAM P46038). Two thoracic spines developed in $11^{\text {th }}$ thoracic segment on right side. Area has been injured and produced a 'L'-shaped injury. (B) Close up of injury and recovery (white arrows). (C, D) Eccaparadoxides pradoanus (Verneuil and Barrande in Prado et al., 1860) from Purujosa Red Beds, Murero Formation (Cambrian Series 3, Drumian), Iberian Chains, Spain (MPZ 2017/1088). Multiple thorax spines developed in $16^{\text {th }}$ and $17^{\text {th }}$ thoracic segments on left side. (D) Close up of injury and spine recovery (white arrows). Scale bars (A, C) 1 cm; (B) 0.125 cm; (D) 0.5 cm. Image credit: (A, B) Russell Bicknell; (C, D) Samuel Zamora. 


\begin{tabular}{llll}
\hline Species and specimen counts & Cephalothorax & Thoracetron & Appendages \\
\hline Carcinoscorpius rotundicauda $(\boldsymbol{n}=\mathbf{1 4})$ & 1 & 2 & 0 \\
Limulus polyphemus $(\boldsymbol{n}=\mathbf{8 8})$ & 0 & 1 & 1 \\
Tachypleus gigas $(\boldsymbol{n}=\mathbf{1 7})$ & 5 & 1 & 0 \\
Tachypleus tridentatus $(\boldsymbol{n}=\mathbf{8})$ & 1 & 0 & 0 \\
\hline
\end{tabular}

Table 1: Summary of abnormal YPM IZ xiphosurid specimens considered here. Carcinoscorpius rotundicauda abnormalities are most

commonly on the thoracetron and telson. Limulus polyphemus abnormalities are most commonly found on the telson. Tachypleus gigas

abnormalities are most commonly incurred on the cephalothorax. Tachypleus tridentatus has injuries incurred equally on the cephalothorax,

thoracetron and telson. Counts of all specimens in the collection are also presented. 